\title{
Arboreal Coleoptera Associated with Leucosidea sericea (Rosaceae) at the Golden Gate Highlands National Park
}

\author{
SCHALK LOUW
}

\begin{abstract}
Louw, Schalk, 1988. Arboreal Coleoptera associated with Leucosidea sericea (Rosaceae) at the Golden Gate Highlands National Park. - Koedoe 31: 53-70. Pretoria. ISSN 0075-6458.

An analysis was made of arboreal Coleoptera on Leucosidea sericea from the Golden Gate Highlands National Park in the north-eastern Orange Free State, Republic of South Africa. Five sites were selected from which samples were taken, using a beating technique, at equal intensity, during 13 consecutive months. A total of 117 species representing 35 families were recorded and allocated to four guilds, namely phytophages ( 47 species), predators (44 species), scavengers ( 16 species) and tourists (10 species). This diversity is attributed to the structural complexity and range of the host plant. The scarcity of a large number of these species is primarily ascribed to a high seasonal turnover rate. Species diversity and numbers of individuals were found to vary between the different study sites and are attributed to the growth stage and condition of the host plant, as well as the effect of sun and shade on activity cycles and the choice of feeding levels.
\end{abstract}

Key words: Golden Gate Highlands National Park, Leucosidea sericea. arboreal Coleoptera, composition.

Schalk Louw, Department of Entomology, National Museum, P.O. Box 266, Bloemfontein, 9300 Republic of South Africa.

\section{Introduction}

Leucosidea sericea Ecklon \& Zeyher (Rosaceae), vernacularly known as ouhout, is a small, much-branched tree which grows up to seven $\mathrm{m}$ high and commonly occurs at high altitudes in the eastern parts of southern Africa (Coates Palgrave 1977). It is characterised by brown bark which flakes off in strips and alternate, compound leaves with marginally serrated leaflets which bear silky hairs on the ventral surface. The flowers and fruit are small and densely clustered and during winter leaf shedding can be intense, especially in older trees. In Natal and the eastern Cape Province especially, Leucosidea is reported to be of agricultural concern as it invades overgrazed and disturbed areas, forming impenetrable thickets which prohibit livestock from reaching grazing areas.

Elsewhere in the world Rosaceae plants are known to harbour an extraordinary number of insects (Southwood 1961, 1977; Lawton \& Schroder 1977; Leather 1986). In southern Africa, however, nothing is known about the local Rosaceae and their arthropod associates. In fact, arthropod communities on plants are just beginning to be studied and it is only Moran (1980), Moran \& Southwood (1982) and Grant \& Moran (1986) who have made significant contributions in this regard. With this scientific gap in mind, the present study, which encompasses only the Coleoptera, was undertaken to serve as an initia- 
tion for eventual detailed studies on the arthropod communities associated with Rosaceae. In the case of Leucosidea sericea the ultimate goal will be to identify trends in arthropod communities supported by plants which could become the topic of an environmental-agricultural debate.

For the purposes of this study, arboreal Coleoptera are defined as all those Coleoptera captured in beating samples.

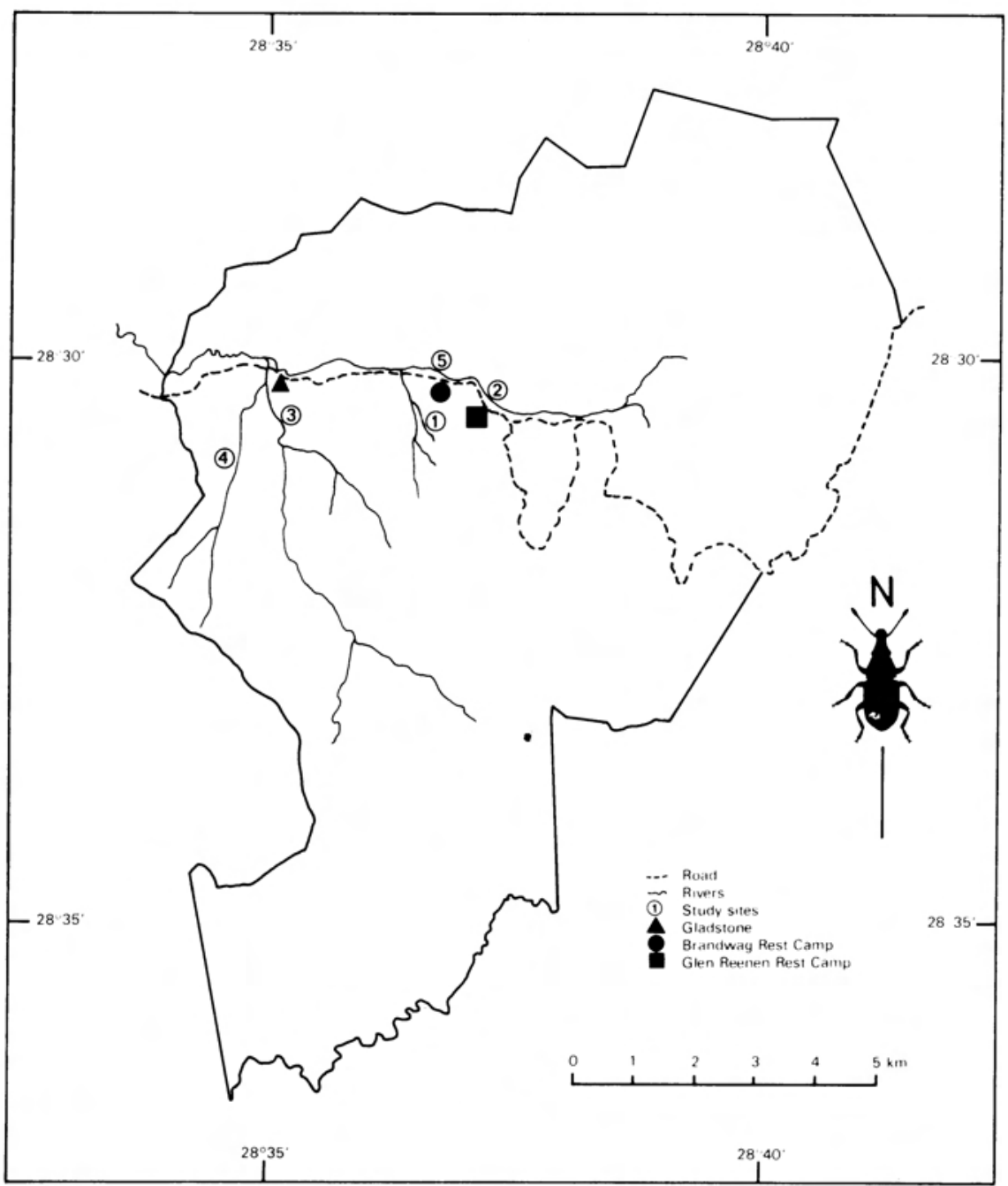

Fig. 1. A map of the Golden Gate Highlands National Park indicating the location of the five study sites. 


\section{Study area}

The Golden Gate Highlands National Park (GGHNP) covers an area of 6241 hectares and is situated in the foothills of the Maluti Mountains in the north-eastern Orange Free State. The park has a severely undulated topography and lies between $1892 \mathrm{~m}$ and $2835 \mathrm{~m}$ above sea level. It falls within the summer rainfall region and receives an average rainfall of 764 $\mathrm{mm}$ per annum, most of it during November to April. The summers are mild. Winters are generally very cold with occasional snow at the higher altitudes. Frost occurs during winter nights. The mountain slopes are mostly grass-covered. Stands of Leucosidea sericea flank the streams and form dense thickets in the ravines.

The areas of the five beating sites were chosen to represent a variety of environmental and Leucosidea-growth stage conditions in the park (Fig. 1). The stands at each of the sites were fairly homogeneous and form more or less isolated patches surrounded by large areas of grassveld. Specific site descriptions are as follows:

Site 1 . On the Holkrans trail on a flat area at the base of the mountain directly adjacent to a small stream which cuts deeply through the surrounding terrain. The Leucosidea trees are all young and shrub-like in appearance and approximately $1 \mathrm{~m}$ in height (Fig. 2a).

Site 2. Flanking the Small Caledon River at Glen Reenen. The trees are all fully grown and healthy and at most places the stand is very dense, resulting in permanently shaded beating levels. (Fig. 2b).

Site 3 . On the Rhebuck trail in a flat area where a semi-permanent stream meanders. The Leucosidea trees are all fully grown and healthy, forming a relatively sparse stand and resulting in partially shaded beating levels (Fig. 2c).

Site 4 . At Noord Brabant directly adjacent to a stream which is dry for the greater part of the year. The trees are fully grown and healthy and the stand is relatively sparse, resulting in partially shaded beating levels (Fig. 2d).

Site 5. Directly adjacent to the Small Caledon River at the foot of the Brandwag sandstone cliffs. The Leucosidea trees, although fully grown and forming a dense stand, are mostly dying back and contain numerous dead or dying branches (Fig. 2e).

\section{Methods}

All samples were collected by employing the beating technique (Southwood 1978) once a month from September 1985 to September 1986 inclusive, between the hour $09 \mathrm{~h} 30$ and $16 \mathrm{~h} 00$. At each site 50 trees were selected and the branches of these were beaten from ground level to a height of approximately 2,5 metres. Throughout the study period the same site was worked during the same time of day. A stout stick was used for beating and a canvas tray, measuring $75 \mathrm{~cm} \times 75 \mathrm{~cm}$, supported by wooden crossribs was used to collect the dislodged beetles. These were aspirated into vials and killed with ethyl acetate. Samples were kept separate for each site and sorted the same day. Sorted samples were then processed and classified to family level or lower.

Guild terminology follows Root (1967) and Moran \& Southwood (1982). For this study the months September to November were considered as spring, December to February as summer, March to May as autumn, and June to August as winter.

\section{Results}

A relatively high number of 117 species of Coleoptera, representing 35 families, was recorded on the above-ground portions of Leucosidea sericea (Table 1). These species were allocated to four guilds, viz. chewing phytophages, predators, scavengers and tourists. (Species in the tourist guild and 

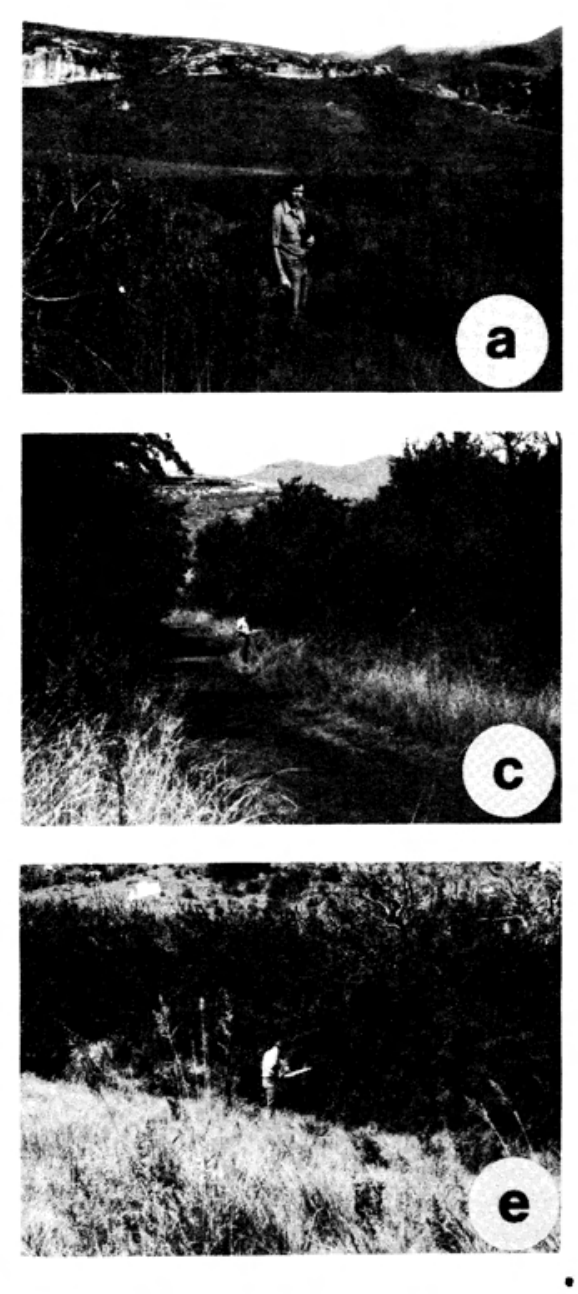
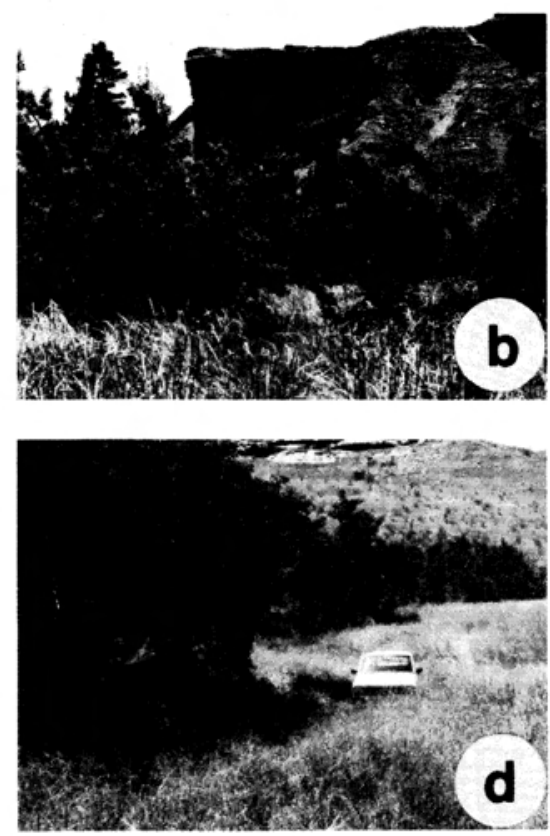

Fig. 2. The study sites at the Golden Gate Highlands National Park. a. Site 1 on Holkrans trail. b. Site 2 at Glen Reenen. c. Site 3 on Rhebuck Trail. d. Site 4 at Noord Brabant. e. Site 5 at Brandwag.

the reasons for this allocation are as follows: Gonipterus scutellatus and Trichostetha fascicularis are host specific on Eucalyptus and Protea respectively; Odontoloma is a coprophage and is presumably only on the plant to collect bird droppings (C.H. Scholtz, pers. comm.); Helodidae are semi-aquatic scavengers; Apionidae have never been recorded to have Rosaceae hosts (M. Alonso-Zarazaga, pers. comm.)). In terms of both species diversity and numbers of individuals the phytophages and predators are by far the most common in this guild composition (Fig. 3a \& 3b). From a diversity point of view, in particular, the Curculionidae (15 species) and Coccinellidae (18 species) form the most common phytophagous and predaceous families respectively, with Alleculinae sp. a (Tenebrionidae) the most numerous phytophagous species and Cybocephalus sp. a (Cybocephalidae) the most numerous predator (Table 1). The phytophagous and predatory guilds comprise an unequal number of species and individuals and the number of families recorded in each is also clearly different (Fig. 3c). 


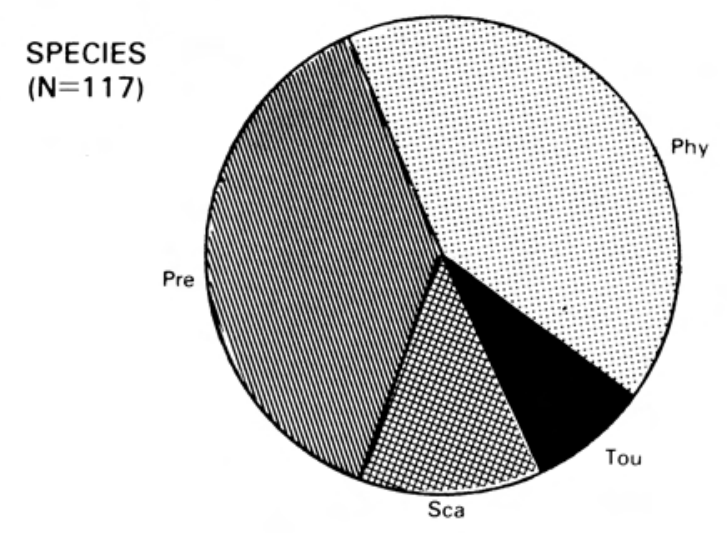

a

b
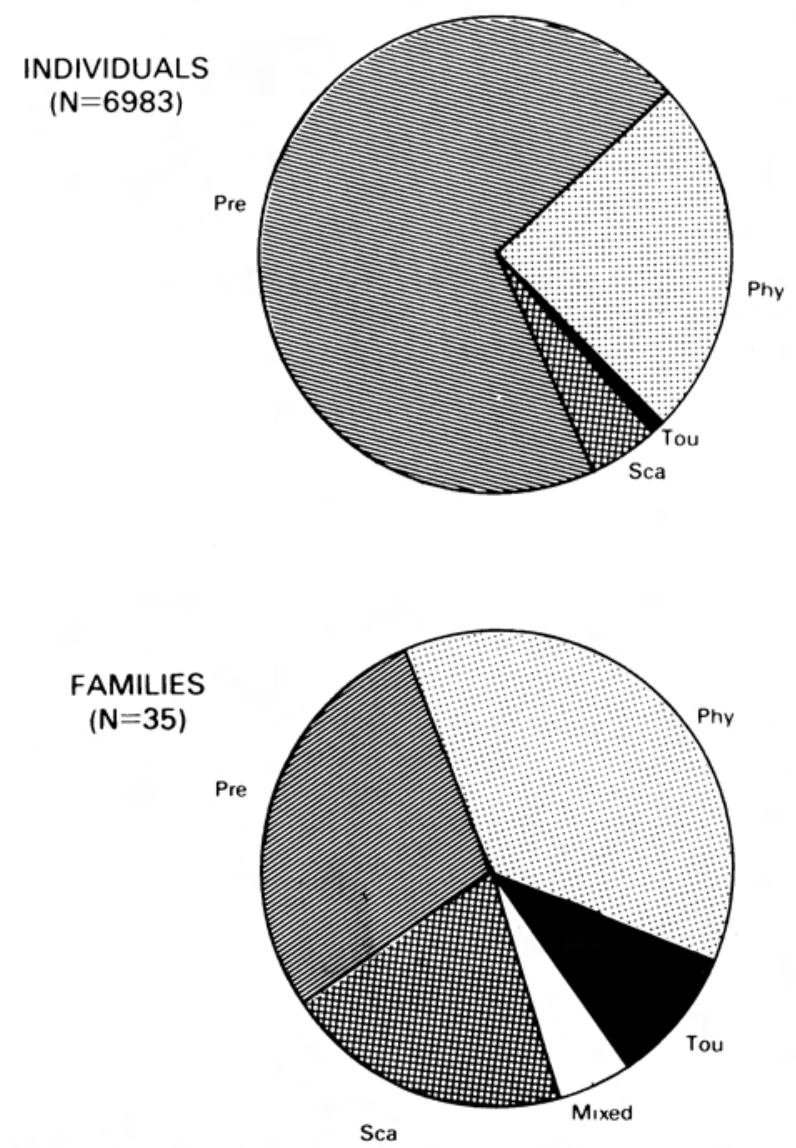

Fig. 3. Guild structure of the arboreal Coleoptera from Leucosidea sericea at the Golden Gate Highlands National Park expressed in numbers of species (a), numbers of individuals (b) and numbers of families (c). (Phy $=$ phytophages. Pre $=$ predators. $\mathrm{Sca}=$ scavengers. Tou $=$ tourists.) 


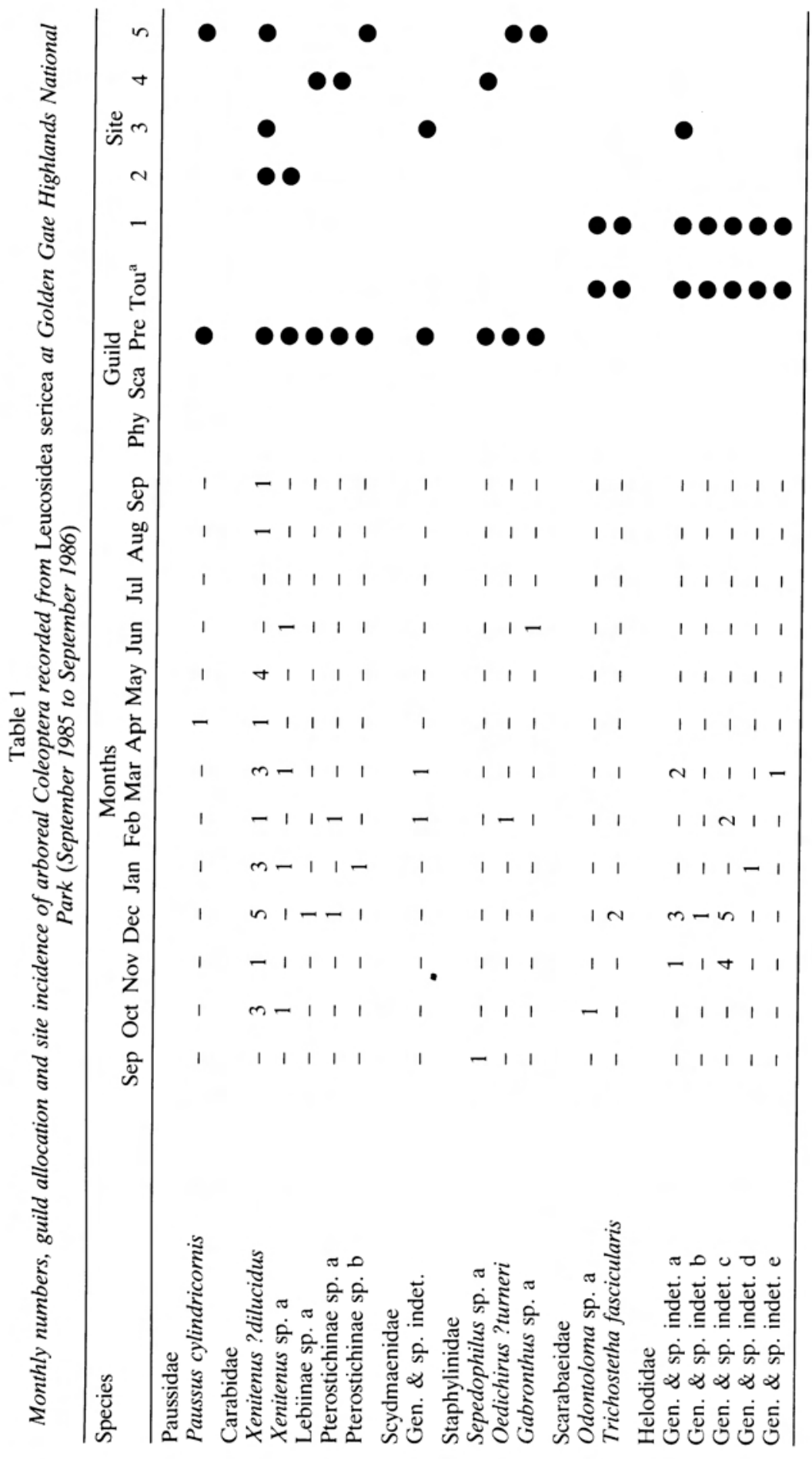




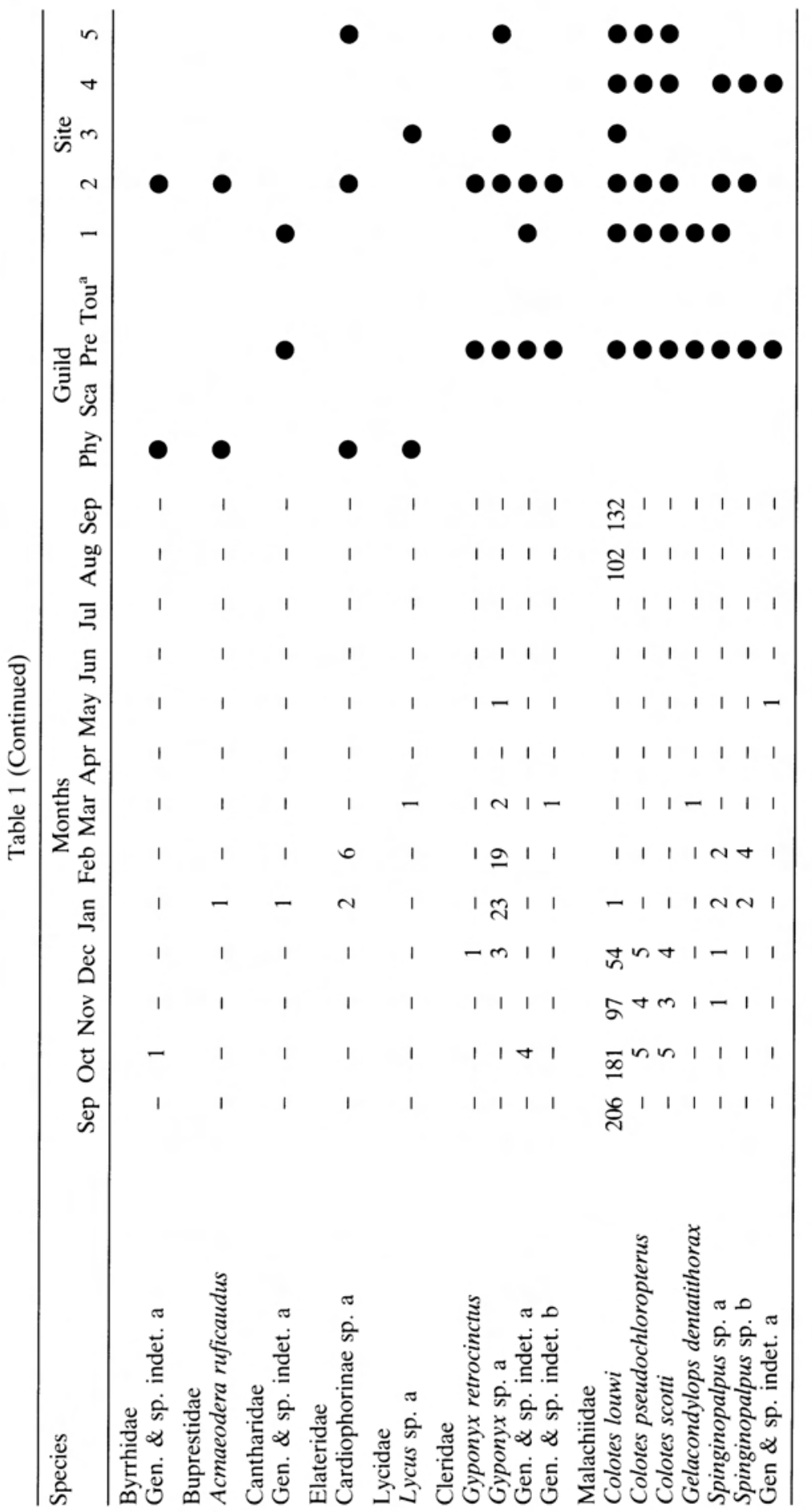




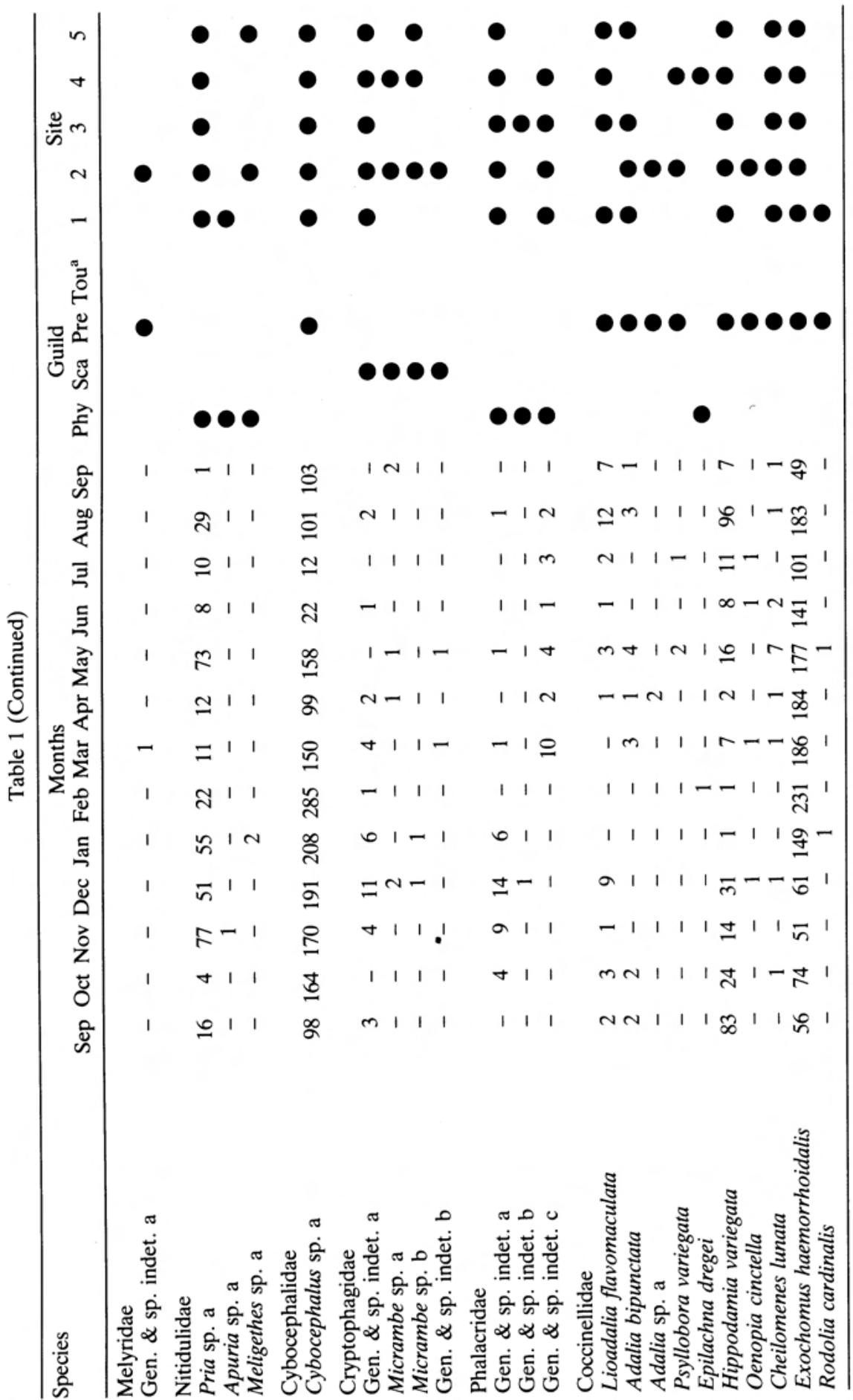




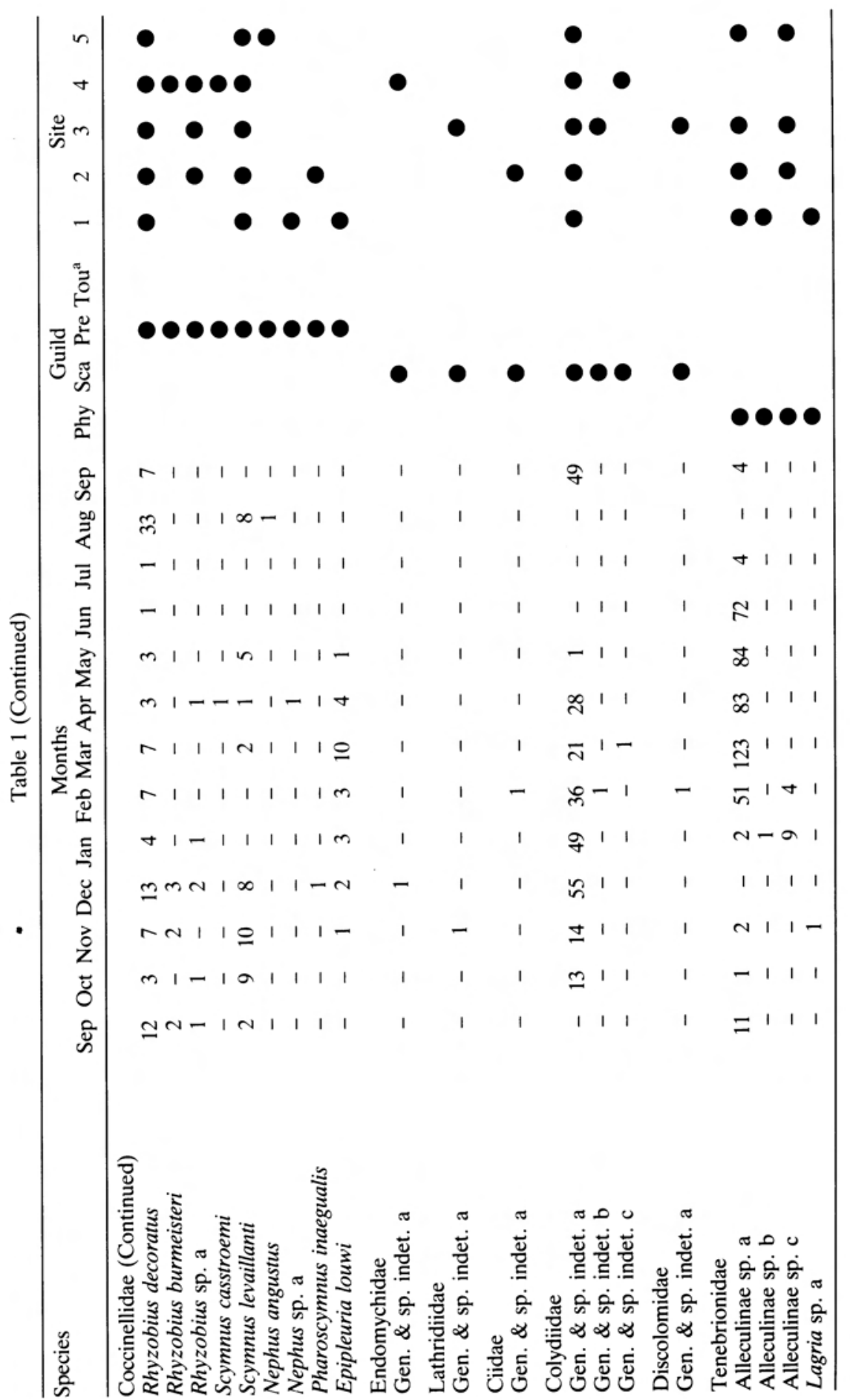




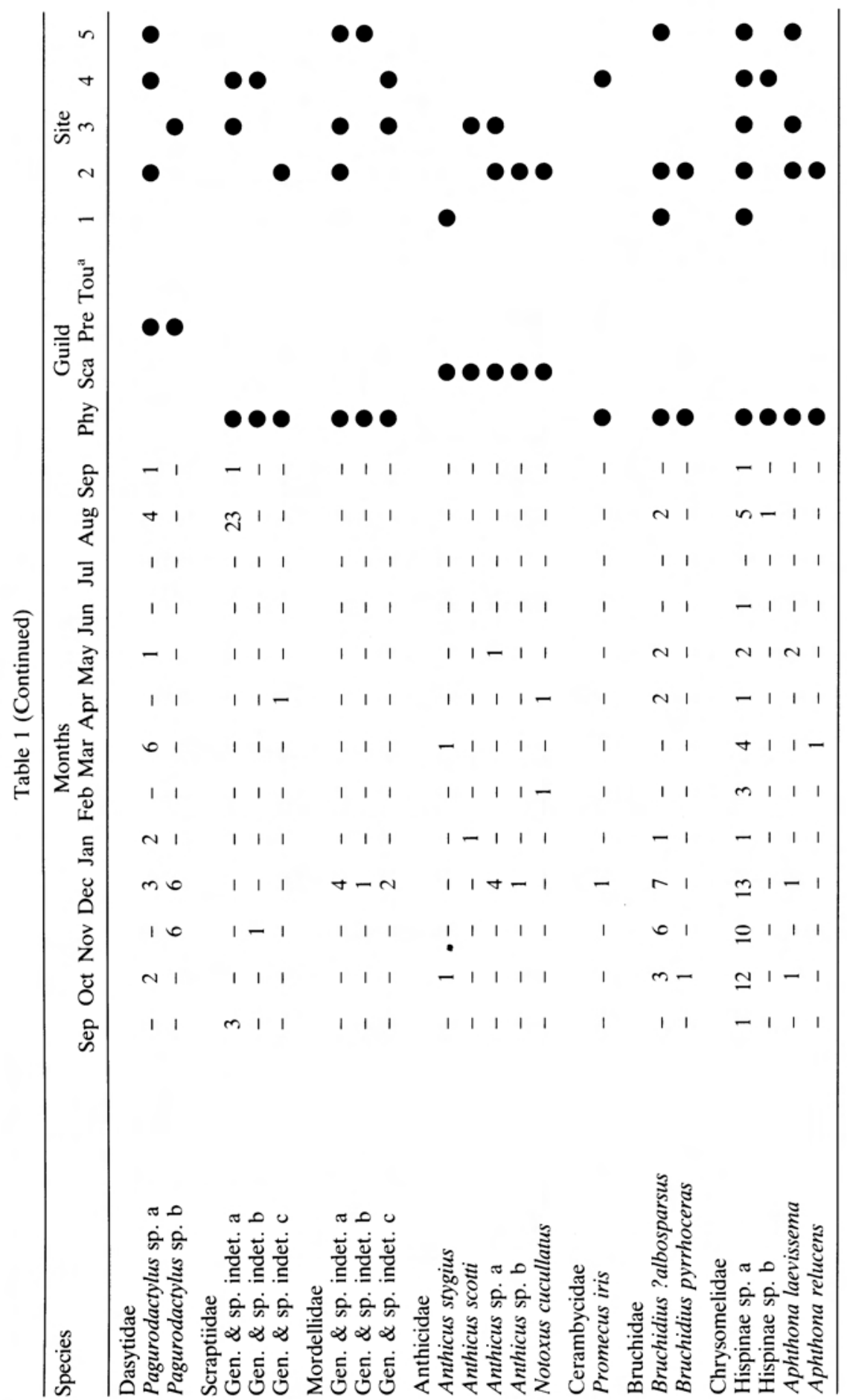




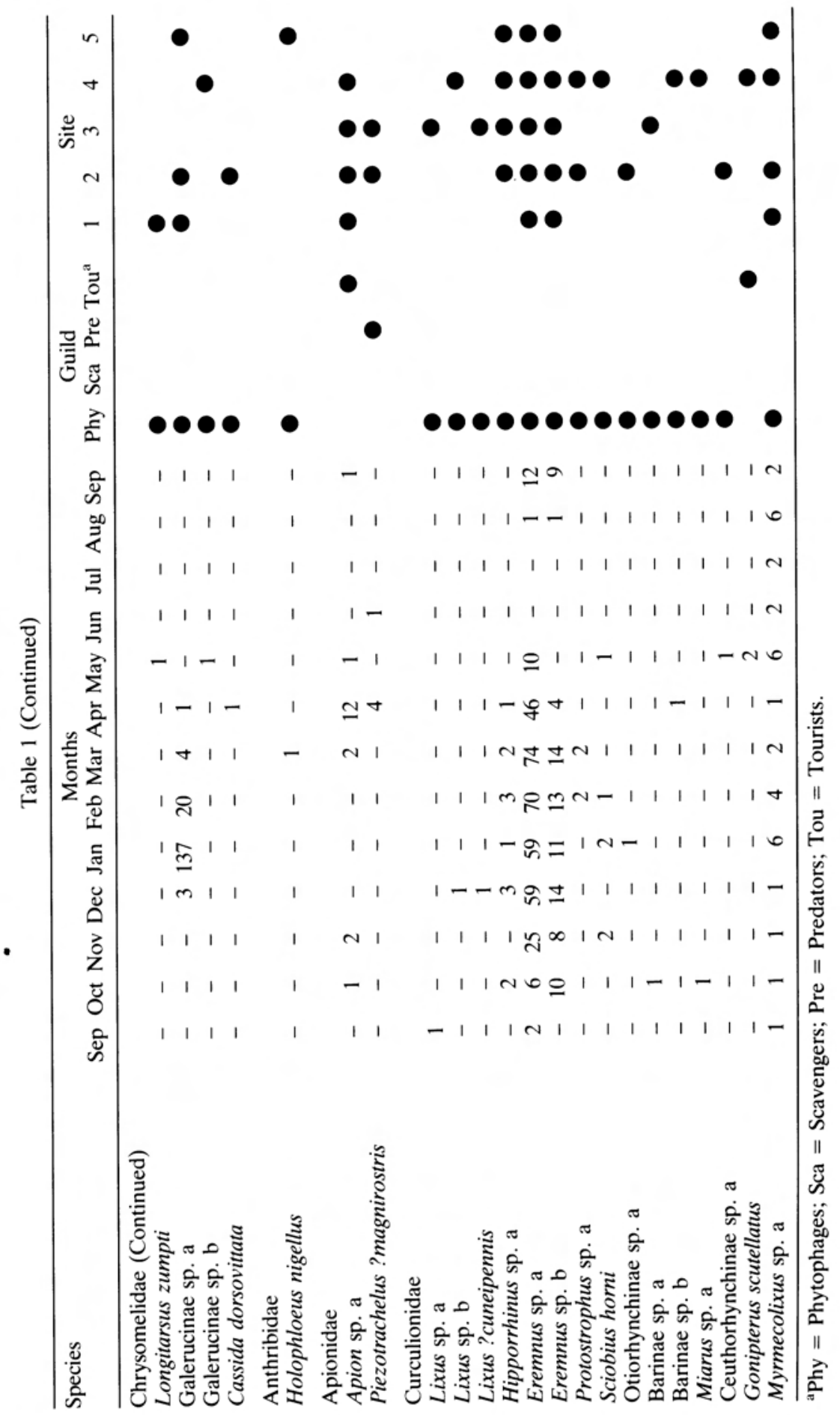




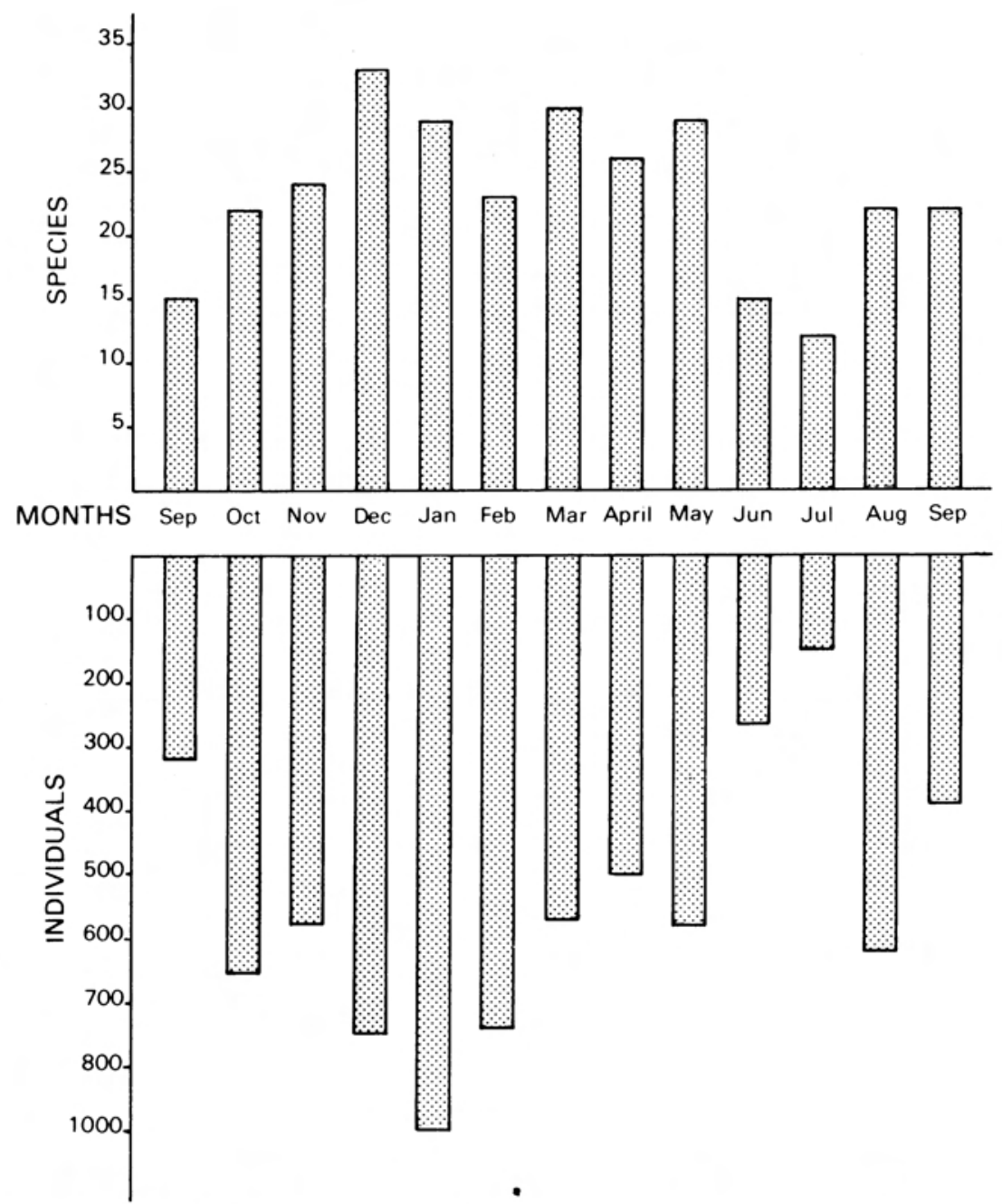

Fig. 4. The monthly species diversity of arboreal Coleoptera on Leucosidea sericea at the Golden Gate Highlands National Park plotted opposite the respective numbers of recorded individuals.

Total numbers of species and individuals recorded during each of the 13 months of the study are shown in Fig. 4 and Appendix 1 and, with the exception of mid-winter (June and July), no marked seasonal fluctuation is evident. When specific species occurrences are considered, however, as many as 62 species $(53 \%)$ are single month records, whilst only $5 \%$ of the species viz. Pria, Cybocephalus, Hippodamia variegata, Exochomus haemorrhoidalis, Rhyzobius decoratus and Myrmecolixus were present throughout the survey (Fig. 5). 


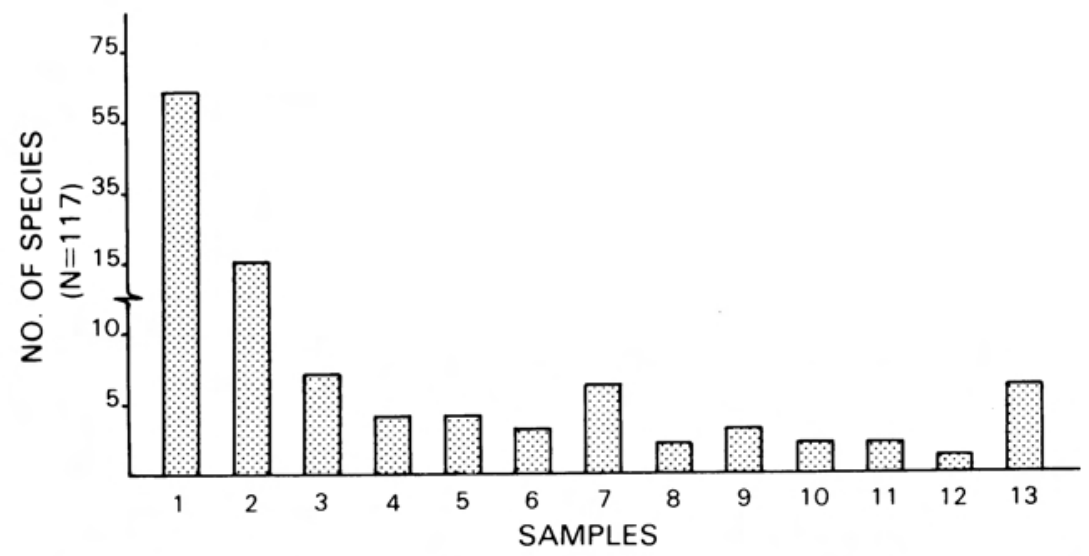

Fig. 5. The scarcity - commonness index of the Coleoptera recorded on Leucosidea sericea at the Golden Gate Highlands National Park from September 1985 to September 1986, inclusive.

The occurrence of species and individuals at each of the five study sites is depicted in Table 1 and Fig. 6. Brief mention should be made here regarding the complement of Coleoptera associated with each of the sampling sites:

At site 1, with its stand of young trees, there was a high incidence of tourists. Here the most common phytophages were a tenebrionid (Alleculinae sp. a) and a chrysomelid (Galerucinae sp. a). The most common predators were Exochomus haemorrhoidalis, Hippodamia variegata and Colotes louwi.

At site 2, where most of the beating levels were in permanent shade, a Pria sp. and two species of Eremnus were the most common phytophages, and a Cybocephalus sp., E. haemorrhoidalis, H. variegata and $C$.

- louwi the most common predators. A colydiid (Colydiidae sp. a) was by far the most common scavenger.

At sites 3, 4 and 5 where the beating levels were more or less exposed to equal periods of sunlight and shade, the most common phytophages, predators and scavengers were identical to those of Site 2.

At site 5 where most of the trees are 'stressed' with many dead or dying sections, the total absence of tourists is notable. Furthermore, the myrmecophilous Myrmecolixus was more common here than at all the other sites together, a phenomenon ascribed to the association of the ant host Crematogaster with the abundant dead Leucosidea wood at this site.

As is shown in the overall guild structure (Fig. 3a and 3b) there is also a striking similarity between the numbers of species and individuals of phytophages and predators at each of the sites individually. 

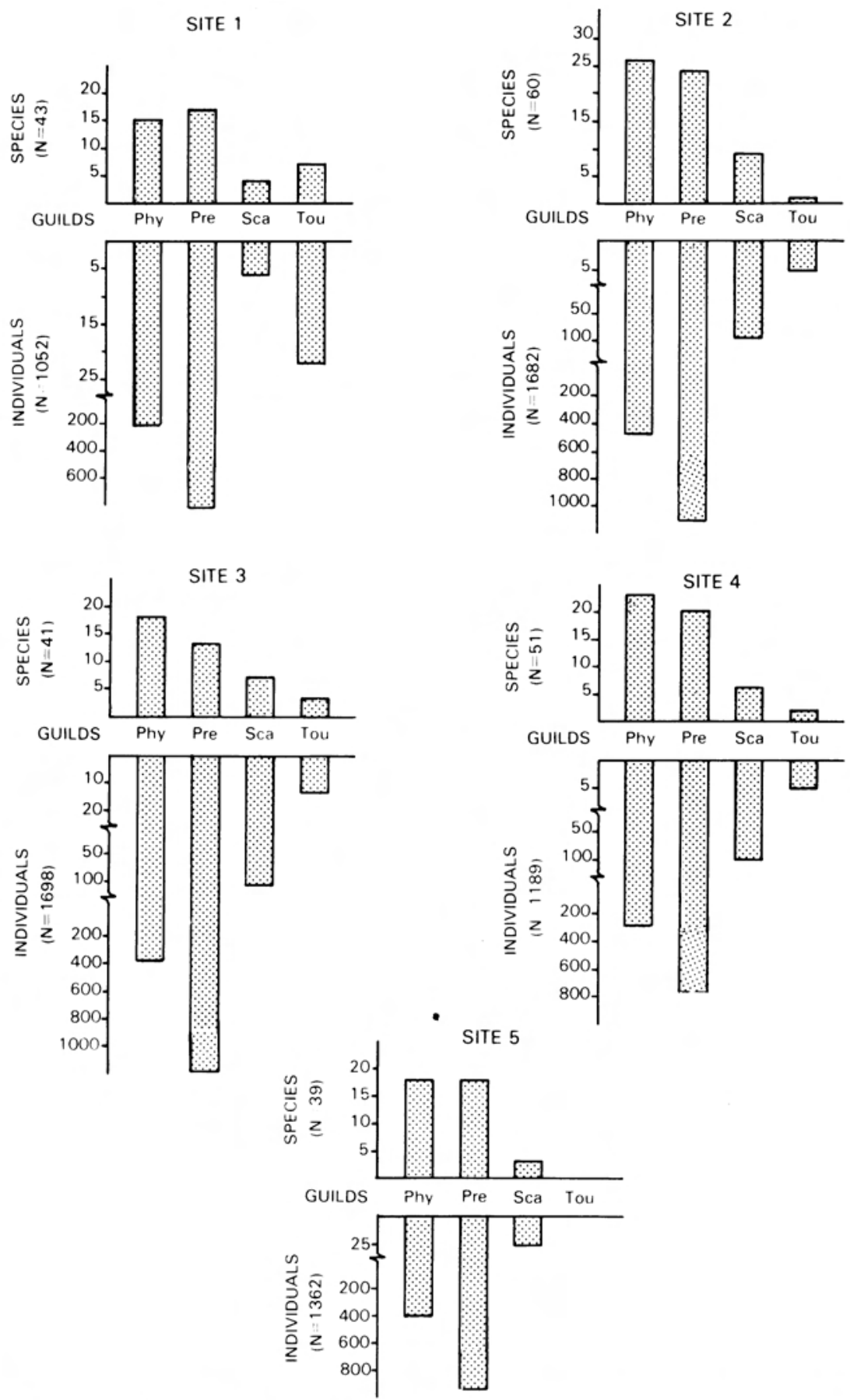

Fig. 6. Guild structure of the arboreal Coleoptera on Leucosidea sericea at each of the study sites at the Golden Gate Highlands National Park plotted opposite the respective numbers of recorded individuals. 
Differences in the growth stage (e.g. young trees at Site 1), condition (e.g. 'stressed' trees at Site 5) of Leucosidea, and differences in the sun/ shade factor all appear to influence the number of species recorded at each of the sites.

\section{Discussion}

Although only the Coleoptera-associates of the above-ground parts of Leucosidea sericea were studied, certain trends regarding the composition of the arthropod communities on these trees can be pointed out.

It was shown by Moran \& Southwood (1982) that, on average, the majority of arthropod species on broad-leaved trees which they studied were phytophages and that they, in fact, determined a proportional number of predators, thus pointing to the probable existence of a proportional constancy pattern between the two guilds. Based on species diversity and numbers of individuals the phytophages and predators are also the guilds most closely associated with Leucosidea (Fig. 3a and 3b). The species and families comprising these two guilds also appear to resemble the proportional constancy pattern of Moran \& Southwood (1982) at each of the five study sites, regardless of growth stage or condition of the host plant (Table 2). Whereas Moran \& Southwood (1982) found that on the trees they studied there was a general tendency for the phytophagous arthropods to be smaller and the predaceous arthropods to be larger, this does not seem to be the case with the Coleoptera on Leucosidea in this study. Approximately $41 \%$ of the phytophagous species and $25 \%$ of the predaceous species are longer than $7 \mathrm{~mm}$ in length, suggesting that the guild most intimately associated with Leucosidea (i.e. those feeding on its different parts), is also the guild with the highest biomass.

Out of a total of a 117 species as many as $62(52 \%)$ of the species were recorded only once during the survey, while a further $30(26 \%)$ species were recorded less than six times (Fig. 5). In an attempt to provide a possible explanation for this phenomenon of 'high diversity - high scarcity', three issues are consi- dered. Firstly, Leucosidea is a plant with large seasonal changes in foliage and other phenological characteristics (Coates Palgrave 1977). Such plants, according to Lawton (1983), should display a high seasonal turnover of their fauna. Secondly, Leucosidea is also structurally complex (Coates Palgrave

Table 2

Numbers of species recorded in each of the guilds at the five different Leucosidea sericea study sites at Golden Gate Highlands

National Park

\begin{tabular}{lrrrrr}
\hline Guild & \multicolumn{5}{c}{ Study site } \\
& 1 & \multicolumn{1}{c}{2} & \multicolumn{1}{c}{3} & \multicolumn{1}{c}{4} & \multicolumn{1}{c}{5} \\
\hline Phytophages & 14 & 25 & 17 & 22 & 17 \\
Predators & 18 & 25 & 14 & 21 & 19 \\
Scavengers & 4 & 9 & 7 & 6 & 3 \\
Tourists & 7 & 1 & 3 & 3 & 0 \\
\hline
\end{tabular}


1977) and should therefore have a high equilibrium species pool (Lawton \& Schroder 1977; Lawton 1978; Strong, Lawton \& Southwood 1984) by permitting a greater niche diversification (for feeding, oviposition, overwintering, shelter and enemy-free space). Thirdly, classical interspecific competition, which has always been considered one of the determinants of species saturation levels on plants, seems, in fact, to be weak and infrequent (Lawton $\&$ Strong 1981). These authors contend that most community trends of insects on plants are determined by the phytophagous guild which in turn are governed by autecological factors (such as climate, host plant phenology, food plant patchiness and seasonal changes in chemical and physical composition of the host plant) in combination with the regulating impact of natural enemies. At the GGHNP, except for a few isolated occurrences, there are practically no other trees, with the result that the widespread Leucosidea with its high degree of niche diversity and presumed limited competition levels, must be regarded as a virtual oasis by the arboreal arthropod fauna of the area. The resultant big species pool is even further enlarged due to the high seasonal turnover rate caused by the changing phenology of the plant. Species utilising the plant for reasons other than feeding (e.g. tourists and species hiding from enemies) will obviously not necessarily have a turnover rate that is seasonally dependent. Although it is by no means implied that these are the causal mechanisms underlying the high percentage of scarce species in the diverse community encountered during this study, it is tempting to speculate that, along these lines of reasoning, the answer lies partially in community interactions (Heatwole \& Levins 1972) and partially in chance assortment of species in response to the physical environment of the tree (Simberloff 1978).

Differences in host plant quality and growth stage seem to have an influence on the arthropod associates of Leucosidea. On the young trees at Site 1 the most common chewers (a galerucine chrysomelid and an alleculine tenebrionid) were different from those on the older trees at the other sites. This could be due to different feeding preferences and a selective response to the higher nutritional values of the younger plants. Tourists at this site are relatively abundant, presumably because of the suitable vantage levels these small, sparse plants provide. By contrast Site 5, with its stand of dense, 'stressed' trees appears unfavourable as it harbours no tourists and has a low number of phytophages. It therefore seems evident that in Leucosidea, as with bracken fern in Britain (MacGarvin, Lawton \& Heads 1986), the different growth stages, phenophases and specific portions of the plant are all perceived in an unequal manner by the different phytophagous species. This, in turn, has an indirect influence on the other guilds. What it suggests is that in the midst of apparent plenty, insects on plants can actually be resource limited (Strong, Lawton \& Southwood 1984).

It is known that sun and shade on a host plant can have an effect on the abundance of the associated phytophagous insects (Maiorana 1981; White 1984; MacGarvin, Lawton \& Heads 1986). Observations on Leucosidea have shown that the Coleoptera apparently preferred the sunny parts of the plants early in the morning and late in the afternoon, while during the heat of the day the shaded parts of the plants were more popular. This should be interpreted as a behavioural trait by the insects to regulate their body temperatures and has little to do with feeding preferences. However, it is notable that at Site 2, the 
only site where the beating levels were more or less in permanent shade, the highest number of species and individuals were recorded (Fig. 6). This suggests that on Leucosidea, levels of phytophagy as well as general arthropod incidence will be greater in the shade.

\section{Conclusions}

At the GGHNP Leucosidea sericea was found to harbour 117 species of arboreal Coleoptera representing as many as 35 different families. Although the array of other arthropod communities on Leucosidea has not yet been studied, all indications are that the total number of associates will be considerable. Because of the abundance of Leucosidea and the scarcity of other trees in the area, Leucosidea, as a habitat for arboreal arthropods, is seen as having an important bearing on the overall trophic structure of the GGHNP.

\section{Acknowledgements}

I am grateful to the following persons and institutions: R. Oberprieler, A. Smetana, C. Scholtz, E. Holm, C. von Hayek, W. Wittmer, S. Endrödy-Younga, H. Fursch, J. van Hille, J. Decelle, G. Scherer, R. Frieser, M. Alonso-Zarazaga and R. Anderson for the identification of material; R. Earlé, H. du Toit and C. Pieterse for assistance during field work; my assistant Annamé Wels for valuable field assistance, sorting and processing collected material and preparing manuscript figures; D. Garstang, K. Kay and G. Groenewald of the GGHNP for providing facilities; the National Parks Board of Trustees for permission to carry out this project at the GGHNP; and the Council and Director of the National Museum, Bloemfontein, for supporting the project.

\section{References}

COATES PAlGRAVE, K. 1977. Trees of Southern Africa. Cape Town: C. Struik.

GRANT, S. and V.C. MORAN. 1986. The effects of foraging ants on arboreal insect herbivores in an undisturbed woodland savanna. Ecol. Entomol. 11(1): 83-93.

HEATWOLE, H. and R. LEVINS. 1972. Trophic structure stability and faunal change during recolonization. Ecology 53: 531-534.

LAWTON, J.H. 1978. Host plant influences on insect diversity: the effects of space and time. Pp. 105-125. In: MOUND, L.A. and N. WALOFF (eds.). Diversity of Insect Faunas. Symp. Roy. ent. Soc., London, No 9.

LAWTON, J.H. 1983. Plant architecture and the diversity of phytophagous insects. A. Rev. Ent. 28: 23-39.

LAWTON, J.H. and D. SCHRODER. 1977. Effects of plant type, size of geographical range and taxonomic isolation on number of insect species associated with British plants. Nature 265: 137-140.

LAWTON, J.H. and D. STRONG. 1981. Community patterns and competition in folivorous insects. Am. Nat. 118: 317-338.

LEATHER, S.R. 1986. Insect species richness of the British Rosaceae: the importance of host range, plant architecture, age of establishment, taxonomic isolation and speciesarea relationships. J. Anim. Ecol. 55: 841-860.

MACGARVIN, M., J.H. LAWTON and P.A. HEADS. 1986. The herbivore insect communities of open and woodland bracken: observations, experiments and habitat manipulations. Oikos 47: 135-148.

MAIORANA, V.C. 1981. Herbivory in sun and shade. Biol. J. Linn. Soc. 15: 151-156. 
MORAN, V.C. 1980. Interactions between phytophagous insects and their Opuntia hosts. Ecol. Entomol. 5: 153-164.

MORAN, V.C. and T.R.E. SOUTHWOOD. 1982. The guild composition of arthropod communities in trees. J. Anim. Ecol. 51: 289-306.

ROOT, R.B. 1967. The niche exploitation pattern of the Blue-gray Gnatcatcher. Ecol. Monogr. 37: 317-350.

SIMBERLOFF, D.S. 1978. Colonization of islands by insects: immigration, distinction and diversity Pp. 139-153. In: MOUND, L.A. and N. WALOFF (eds.). Diversity of Insect Faunas. Symp. Roy. ent. Soc. London No. 9.

SOUTHWOOD, T.R.E. 1961. The number of species of insect associated with various trees. J. Anim. Ecol. 30: 1-8.

SOUTHWOOD, T.R.E. 1977. The stability of the trophic milieu, its influence on the evolution of behaviour and of responsiveness to trophic signals. Coll. Int. CNRS 265: 471-493.

SOUTHWOOD, T.R.E. 1978. Ecological Methods, with Particular Reference to the Study of Insect Populations. London: Chapman \& Hall.

STRONG, D.R., J.H. LAWTON and Sir RICHARD SOUTHWOOD. 1984. Insects on Plants: Community Patterns and Mechanisms. Oxford: Blackwell Scientific Publications.

WHITE, T.C.R. 1984. The abundance of invertebrate herbivores in relation to availability of nitrogen in stressed food plants. Oecologia 63: 90-105.

Appendix 1

Monthly numbers of species (numbers before the slash) and monthly numbers of individuals (numbers after the slash) from Leucosidea sericea at Golden Gate Highlands National Park expressed per study site (September 1985 to September 1986).

\begin{tabular}{lcccccc}
\hline Site No. & \multicolumn{6}{c}{ Months } \\
& Sept & Oct & Nov & Dec & Jan & Feb \\
\hline 1 & $3 / 14$ & $7 / 55$ & $12 / 56$ & $19 / 96$ & $6 / 149$ & $6 / 112$ \\
2 & $6 / 39$ & $16 / 161$ & $13 / 129$ & $19 / 150$ & $19 / 417$ & $13 / 176$ \\
3 & $14 / 226$ & $12 / 223$ & $16 / 230$ & $20 / 226$ & $9 / 136$ & $7 / 159$ \\
4 & $3 / 12$ & $4 / 44$ & $10 / 44$ & $16 / 149$ & $12 / 102$ & $10 / 176$ \\
5 & $3 / 24$ & $12 / 175$ & $15 / 116$ & $19 / 125$ & $10 / 98$ & $14 / 114$ \\
Total & $15 / 315$ & $22 / 658$ & $24 / 575$ & $33 / 746$ & $29 / 902$ & $23 / 737$ \\
\hline \multirow{2}{*}{ Site No. } & Apr & May & Jun & Jul & Aug & Sept \\
\hline 1 & $6 / 81$ & $5 / 113$ & $6 / 83$ & $4 / 18$ & $9 / 110$ & $10 / 50$ \\
2 & $12 / 111$ & $17 / 127$ & $8 / 61$ & $6 / 29$ & $12 / 125$ & $8 / 63$ \\
3 & $13 / 92$ & $13 / 115$ & $6 / 58$ & $6 / 34$ & $10 / 146$ & $12 / 149$ \\
4 & $9 / 85$ & $17 / 104$ & $3 / 23$ & $2 / 9$ & $13 / 112$ & $12 / 113$ \\
5 & $9 / 129$ & $13 / 118$ & $5 / 37$ & $6 / 57$ & $10 / 131$ & $8 / 14$ \\
Total & $26 / 498$ & $29 / 577$ & $15 / 262$ & $12 / 147$ & $22 / 623$ & $22 / 389$ \\
\hline
\end{tabular}

